\title{
Quarter-Sweep Iteration Concept on Conjugate Gradient Normal Residual Method via Second Order Quadrature - Finite Difference Schemes for Solving Fredholm Integro-Differential Equations
}

(Konsep Lelaran Sapuan Suku ke atas Kaedah Kecerunan Konjugat Sisa Biasa menerusi Kesukuan Peringkat Kedua - Beza Terhingga bagi Menyelesaikan Persamaan Integro-pembezaan Fredholm)

\author{
ElayARAJA ARUCHUNAN*, MOHANA SundARAM MUTHUVALU \& JUMAT SUlAimAN
}

\section{ABSTRACT}

In this paper, we have examined the effectiveness of the quarter-sweep iteration concept on conjugate gradient normal residual (CGNR) iterative method by using composite Simpson's $\frac{1}{3}(C S)$ and finite difference (FD) discretization schemes in solving Fredholm integro-differential equations. For comparison purposes, Gauss-Seidel (GS) and the standard or full-and half-sweep CGNR methods namely FSCGNR and HSCGNR are also presented. To validate the efficacy of the proposed method, several analyses were carried out such as computational complexity and percentage reduction on the proposed and existing methods.

Keywords: Conjugate gradients normal residual method; linear Fredholm integro-differential equations; quarter-sweep iteration

\section{ABSTRAK}

Dalam kertas ini, kami telah menganalisis keberkesanan konsep lelaran sapuan suku ke atas kaedah lelaran kecerunan konjugat sisa biasa (CGNR) dengan menggunakan komposit Simpson's $\frac{1}{3}$ (CS) dan beza terhingga (FD) dalam menyelesaikan persamaan integro-pembezaan Fredholm. Bagi tujuan perbandingan, Gauss-Seidel (GS) dan kaedah CGNR biasa atau penuh dan separuh sapuan iaitu FSCGNR dan HSCGNR juga turut dibincangkan. Bagi mengesahkan keberkesanan kaedah yang dicadangkan, beberapa analisis seperti kekompleksan pengiraan dan pengurangan peratusan untuk kedua-dua kaedah yang dicadangkan dan sedia ada telah dijalankan.

Kata kunci: Kaedah lelaran kecerunan konjugat sisa biasa; lelaran sapuan suku; persamaan integro-pembezaan linear Fredholm

\section{INTRODUCTION}

The integro-differential equations (IDEs) have become progressively more important in numerical analysis for elaborating numerous problems of engineering and scientific fields, such as mechanics, physics, chemistry, astronomy, biology, potential theory, electrostatics, nanohydrodynamics and glass-forming processes (Kurt \& Sezer 2008; Rashed 2003; Ren et al. 1999; Wang \& Lin 2005; Yalçinbaş \& Sezer 2000). IDEs are functional equations that include an integral and derivatives of unknown function and they can be classified into Fredholm and Volterra types. In this paper, we focus on Fredholm types of first order integro-differential equations (IDEs) as follows

$$
\begin{aligned}
& \lambda y^{\prime}(x)-p(x) y(x)-g(x)- \\
& \lambda \int_{a}^{b} K(x, t) y(t) d t=0, \quad x, t \in(a, b] \\
& y(a)=A_{1},
\end{aligned}
$$

where $K(x, t) g(x)$ and $p(x)$ are known functions: $\lambda$ is the real parameter; and $y(x)$ is the unknown function to be determined. The conditions for the existence and uniqueness of the solution of such problems have been investigated by Agarwal (1983) and Morchalo (1975).

In many application areas, it is necessary to use the numerical approach to obtain an approximation solution for solving the problem (1). Therefore to be solved by numerically, integral and differential parts in the problem (1) had to be discretized to generate the system of linear algebraic equations, which is the basic concept used by researchers. Recently, methods such as Taylor collocation (Karamete \& Sezer 2002), quadrature-difference (Fedetov 2009), Lagrange interpolation (Rashed 2003; Shahsaravan 2012), Taylor polynomial (Yalçinbaş 2002), WaveletGalerkin (Avudainayagam \& Vani 2000), rationalized Haar functions (Maleknejad et al. 2004), Tau (Hosseini \& Shahmorad 2003) and Generalised Minimal Residual 
(Aruchunan \& Sulaiman 2010) methods have been studied in solving of the problem (1). In this paper, quarter-sweep iteration concept applied on discretization schemes and followed by Conjugate Gradient for Normal Residual (CGNR) (Barrett et al. 1993) in solving problem (1).

Profoundly, the proposed Quarter sweep iteration concept on CGNR is inspired by the concept of the half-sweep iterative method. In previous studies, this concept has been introduced by Abdullah (1991) via the explicit decoupled group (EDG) iterative method to solve two-dimensional Poisson equations. The basic idea of the half-sweep iteration is to reduce the computational complexities during iteration process, where it will only consider nearly half of all interior node points in a solution domain. Consequently, the applications of halfsweep iterative methods have been discussed in Abdullah and Ali (1996), Sulaiman et al. (2004a), Aruchunan and Sulaiman (2013, 2012a, 2012b, 2011a), Muthuvalu and Sulaiman (2011) and Muthuvalu et al. (2013). In 2000, Othman and Abdullah extended the concept of halfsweep iteration by introducing the quarter-sweep iterative method via the modified explicit group (MEG) iterative method to solve two-dimensional Poisson equations. Further studies to verify the effectiveness of the quartersweep iterative methods have also been carried out (Aruchunan \& Sulaiman 2011b; Aruchunan et al. 2014, 2013; Muthuvalu \& Sulaiman 2011; Sulaiman et al. 2009, $2004 b$ ). Once again, the quarter-sweep iteration inherits the characteristic of half-sweep iteration in which its implementation process will consider approximately a quarter of all interior node points of the solution domain.

The outline of this paper is organized in following way. In the next section, the formulation of the full-, half- and quarter-sweep iteration concept on CS-FD approximation equations will be elaborated. The latter section of this paper, discussion on the formulations of the FSCGNR, HSCGNR and QSCGNR methods and several numerical experiments will be carried out to emphasise the performance of the proposed CG iterative methods. An analysis on computational complexity is discussed on the following section and the conclusion is provided in the last section.

\section{DISCRETIZATION SCHEME BASED ON COMPLEXITY REDUCTION APPROCHES}

Figure 1 shows the finite grid networks in order to form the full-, half- and quarter-sweep concept on quadrature approximation equations.

Based on Figure 1, the full-, half- and quarter-sweep iterative methods will compute approximate values onto node points of type $\bullet$ only until the convergence criterion is reached. Next, other approximate solutions at remaining points (points of the different type $\bigcirc$ and $\square$ ) are computed by using the direct method (Abdullah 1991; Othman \& Abdullah 2000).
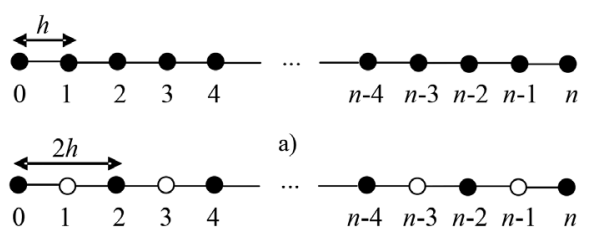

b)

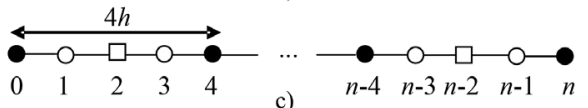

FIGURE 1.a), b) and c) shows the distribution of uniformly node points for the full-, half- and quarter-sweep cases, respectively

\section{DERIVATION OF QUARTER-SWEEP COMPOSITE SIMPSON'S SCHEME}

Aforementioned in the first section, the integral term in (1) will be discretized by CS scheme based on quadrature method to construct an approximation equation. In general, the quadrature formula can be defined as follows:

$$
\begin{aligned}
& \int_{a}^{h} K(x, t) y(t) d t=\frac{h}{3} K\left(x_{0}, t_{0}\right) y_{0}+\frac{4 h}{3} \sum_{j=1,3,5}^{n} K\left(x_{i}, t_{j}\right) y_{j} \\
& +\frac{2 h}{3} \sum_{j=2,4,6}^{n} K\left(x_{i}, t\right) y_{j}+\frac{h}{3} K\left(x_{n}, t_{n}\right) y_{n}+\varepsilon_{n}(y)
\end{aligned}
$$

where $t_{j}(j=0,1, \ldots, n)$ are the abscissas of the partition points of the integration interval $(a, b]$ or quadrature (interpolation) nodes. The standard simpson's $\frac{1}{3}$ in (2) will be modified by combining the half- and quarter-sweep iteration concepts as explained in this section. Therefore, the application of the half- and quarter-sweep iteration concepts, (2) can be illustrated as follows:

$$
\left.\begin{array}{l}
\int_{a}^{h} K(x, t) y(t) d t=\frac{p h}{3} K\left(x_{0}, t_{0}\right) y_{0}+\frac{4 p h}{3} \sum_{j=p, 3 p, 5 p}^{n} K\left(x_{i}, t_{j}\right) y_{j} \\
+\frac{2 p h}{3} \sum_{j=2 p, 4 p, 6 p}^{n} K\left(x_{i}, t\right) y_{j}+\frac{p h}{3} K\left(x_{n}, t_{n}\right) y_{n}+\varepsilon_{n}(y)
\end{array}\right\},
$$

where the constant step size, $h$ is defined as:

$$
h=\frac{1}{n},
$$

and $n$ is the number of subintervals in the interval $(0$, 1). Meanwhile, the value of $p$ corresponds to 1,2 and 4 which represents the full-, half- and quarter-sweep cases, respectively.

\section{DERIVATION OF QUARTER-SWEEP FINITE DIFFERENCE'S SCHEME}

In order to discretize differential terms in (1), the finite difference methods are applied to form an approximation equation. Therefore, for node points $i=1,2, n-1$, the 
central difference scheme is applied. The general form of the central difference scheme is as follows:

$$
y^{\prime}\left(x_{i}\right)=\frac{y\left(x_{i+1}\right)-y\left(x_{i-1}\right)}{2 h}+O\left(h^{2}\right) .
$$

Nevertheless at the point $x_{n}$, this work will propose the second order backward difference scheme as follows:

$$
y^{\prime}\left(x_{n}\right)=\frac{3 y\left(x_{n}\right)-4 y\left(x_{n-1}\right)+y\left(x_{n-2}\right)}{2 h}+O\left(h^{2}\right),
$$

where $h=\frac{1}{n}$ is the size interval between nodes. Both (4) and (5) have the same order of the truncation error. However, the truncation error is mostly under our control because we can choose the number of terms from the expansion of Taylor series. In order to obtain the finite grid work network for formulation of the full-, half- and quarter-sweep finite difference approximation equations over (1), (4) and (5) need to be rewritten in general form as:

$$
\left.\begin{array}{l}
y^{\prime}\left(x_{i}\right) \cong \frac{y\left(x_{i+p}\right)-y\left(x_{i-p}\right)}{2 h}, \quad i=p, 2 p, 3 p, \ldots, n-p \\
y^{\prime}\left(x_{n}\right) \cong \frac{3 y\left(x_{n}\right)-4 y\left(x_{n-p}\right)+y\left(x_{n-2 p}\right)}{2 p h}, \quad i=n
\end{array}\right\} .
$$

Again the value of $p$ corresponds to 1,2 and 4 which represents the full-, half- and quarter-sweep cases, respectively.

\section{FIRST ORDER LINEAR FREDHOLM INTEGRO-DIFFERENTIAL EQUATIONS APPROXIMATION}

In solving LFIDE in (1), combination of proposed discretization schemes (3) and (6) will be applied to the integral and differential parts, respectively, to form approximation equations. In general, formulation of the full-, half- and quarter-sweep approximation equations based on quadrature-difference method for LFIDE can be represented in the form as follows,

$$
\begin{aligned}
& \frac{y_{i+p}-y_{i-p}}{2 p h}-g_{i}-P_{i} y_{i}-\frac{p h}{3} K\left(x_{0}, t_{0}\right) y_{0}-\frac{4 p h}{3} \sum_{j=p, 3 p, 5 p}^{n-p} K\left(x_{i}, t_{j}\right) y_{j} \\
& -\frac{2 p h}{3} \sum_{j=2 p, 4 p, 6 p}^{n-p} K\left(x_{i}, t_{j}\right) y_{j}-\frac{p h}{3} K\left(x_{n}, t_{n}\right) y_{n}=0 \\
& \text { for } i=p, 2 p, \ldots, n-p \\
& \frac{3 y_{i}-4 y_{i-p}-y_{i-2 p}}{2 p h}-g_{i}-P_{i} y_{i}-\frac{p h}{3} K\left(x_{0}, t_{0}\right) y_{0}-\frac{4 p h}{3} \sum_{j=p, 3 p, 5 p}^{n-p} K\left(x_{i}, t_{j}\right) y_{j} \\
& -\frac{2 p h}{3} \sum_{j=2 p, 4 p, 6 p}^{n-p} K\left(x_{i}, t_{j}\right) y_{j}-\frac{p h}{3} K\left(x_{n}, t_{n}\right) y_{n}=0 \\
& \text { for } i=n
\end{aligned}
$$

The linear system generated either by the full-, halfand quarter-sweep approximation equation can be simply shown as:

$$
E \underset{\sim}{y}=\underset{\sim}{f}
$$

where,

$$
\begin{aligned}
& E=\left[\begin{array}{ccccccc}
a_{p, p} & b_{p, 2 p} & d_{p, 3 p} & \ldots & d_{p, n-2 p} & d_{p, n-p} & d_{p, n} \\
c_{2 p, p} & a_{2 p, 2 p} & b_{2 p, 3 p} & \ldots & d_{2 p, n-2 p} & d_{2 p, n-p} & d_{2 p, n} \\
d_{3 p, p} & c_{3 p, 2 p} & a_{3 p, 3 p} & \ldots & d_{3 p, n-2 p} & d_{3 p, n-p} & d_{3 p, n} \\
\vdots & \vdots & \vdots & \ddots & \vdots & \vdots & \vdots \\
d_{n-2 p, p} & d_{n-2 p, 2 p} & d_{n-2 p, 3 p} & \ldots & a_{N-2 p, n-2 p} & b_{n-2 p, n-p} & d_{n-2 p, n} \\
d_{n-p, p} & d_{n-p, 2 p} & d_{n-p, 3 p} & \ldots & c_{n-p, n-2 p} & a_{n-p, n-p} & b_{n-p, n} \\
d_{n, p} & d_{n, 2 p} & d_{n, 3 p} & \ldots & b_{n, 2 p} & e_{n, n-p} & \hbar_{n, n}
\end{array}\right]_{\left(\frac{n}{p}\right) \times\left(\frac{n}{p}\right.} \\
& \underset{\sim}{f}=\left[\begin{array}{c}
2 h g_{p}+\left(2 h A_{p} K_{p, 0}+1\right) y_{0} \\
2 h g_{2 p}+\left(2 h A_{p} K_{2 p, 0}\right) y_{0} \\
2 h g_{3 p}+\left(2 h A_{p} K_{3, p, 0}\right) y_{0} \\
\vdots \\
2 h g_{n-2 p}+\left(2 h A_{p} K_{n-2 p, 0}\right) y_{0} \\
2 h g_{n-p}+\left(2 h A_{p} K_{n-p, 0}\right) y_{0} \\
2 h g_{N}+\left(2 h A_{p} K_{n, 0}\right) y_{0}
\end{array}\right] \text { and } y_{n}=\left[\begin{array}{c}
y_{n}\left(x_{p}\right) \\
y_{n}\left(x_{2 p}\right) \\
y_{n}\left(x_{3 p}\right) \\
\vdots \\
y_{n}\left(x_{n-2 p}\right) \\
y_{n}\left(x_{n-p}\right) \\
y_{n}\left(x_{n}\right)
\end{array}\right] \text {, }
\end{aligned}
$$

in which,

$$
\begin{aligned}
& a_{i, i}=-2 h P_{i}-2 h A_{i} K_{i, i}, \quad b_{i, j}=1-2 h A_{j} K_{i, j}, \\
& c_{i, j}=-1-2 h A_{j} K_{i, j}, d_{i, j}=-2 h A_{j} K_{i, j}, \\
& e_{i, j}=-4-2 h A_{j} K_{i, j}, \hbar_{i, j}=-3-2 h P_{i}-2 h A_{i} K_{i, i} .
\end{aligned}
$$

Obviously $E$ is a dense and non-symmetric coefficient matrix.

\section{FORMULATION OF CONJUGATE GRADIENT FOR NORMAL EQUATION (CGNR) METHOD}

Apparently, the coefficient matrices for (1) are nonsymmetric dense matrix, thus the standard conjugate gradient (CG) iterative method does not work for this type of matrices. This is because, the CG algorithm is best known for solving symmetric positive definite linear systems (Barrett et al. 1993). Therefore, to find a solution for the generated linear systems, (8) will be multiplied by the transpose of the coefficient matrix, $E$ to form symmetric positive definite linear system as follows,

$$
E^{T} E \underset{\sim}{y}=E^{T} \underset{\sim}{f}
$$

where, now the coefficient matrix $E^{T} E$ is symmetric positive definite and the linear system (9) is called as conjugate gradient normal equations (CGNR). The (9) can also be simplified as follows,

$$
E^{*} \underset{\sim}{y}=\underset{\sim}{f^{*}}
$$


Algorithm 1 shows the proposed QSCGNR iterative method based on (1)

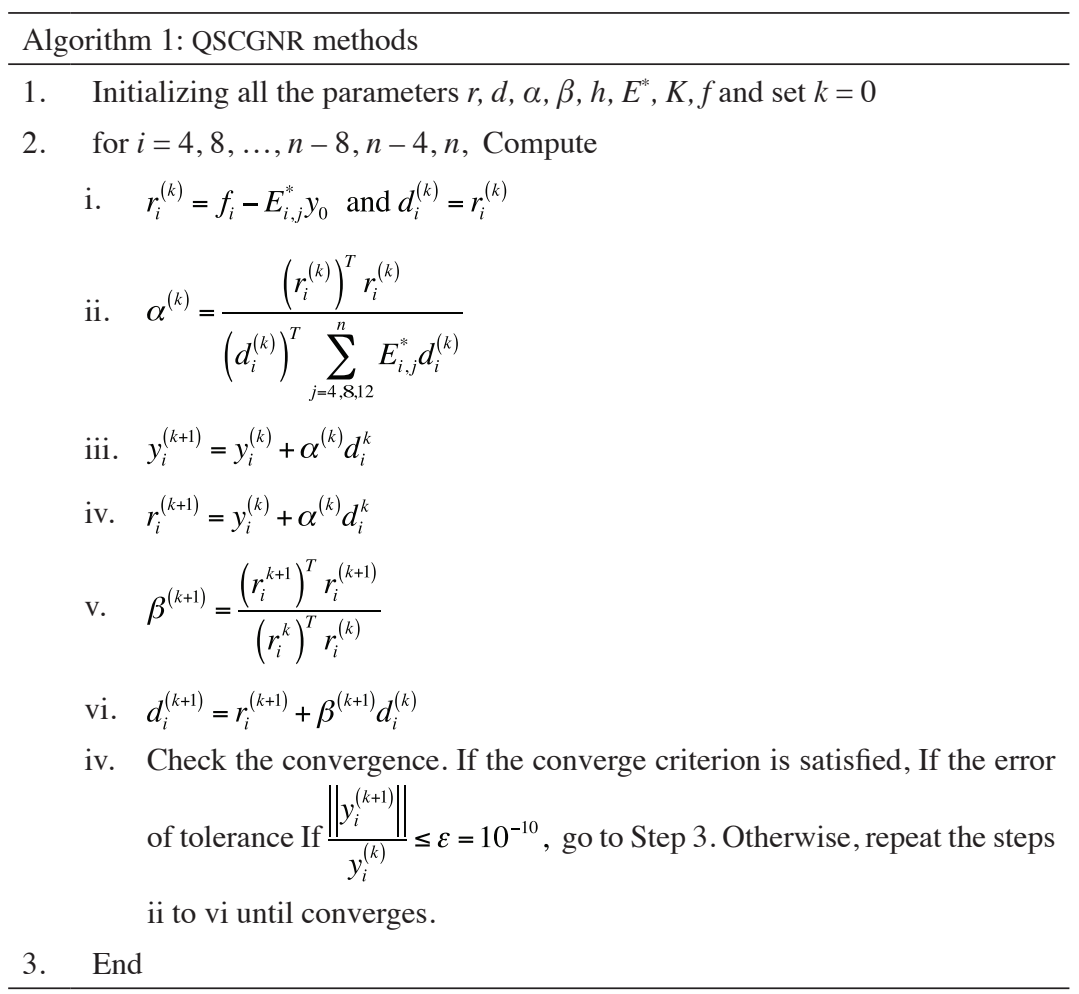

where,

$$
E^{*}=E^{T} E, E^{*}=E^{T} \underset{\sim}{f}
$$

After convergence, additional calculations are required for proposed CGNR iterative methods to compute the remaining points. Therefore, average values are considered to calculate the remaining points as follows,

i). Half-sweep case

$$
y_{i}=\left\{\frac{y_{i-1}+y_{i+1}}{2}, \quad i=1,3,5, n .\right.
$$

ii). Quarter-sweep case

$$
y_{i}=\left\{\begin{array}{ll}
\frac{y_{i-2}+y_{i+2}}{2}, & i=2,4,6, n-2 \\
\frac{y_{i-1}+y_{i+1}}{2}, & i=1,2,3, n
\end{array} .\right.
$$

Whereas, to compute the value for points of type $\square$ is, $\frac{y_{i-2}+y_{i+2}}{2}, i=4,8,12, n-2$ and the value for points of types ○ is, $\frac{y_{i-1}+y_{i+1}}{2}, i=1,3,5, n$.

\section{NUMERICAL TREATMENTS AND DISCUSSION}

In order to evaluate the performances of the family of CGNR iterative methods described in the previous section, numerical experiments were carried out from two problems of linear Fredholm integro-differential equations. Both problems are classified as well posed equations.

Problem 1 (Kajani \& Vencheh 2007):

Consider the type linear FIDE of first order

$$
\begin{aligned}
& y^{\prime}(x)-y(x)+\frac{1}{2} x-\frac{1}{x+1}+\ln (1+x)- \\
& \frac{1}{(\ln 2)^{2}} \int_{0}^{1} \frac{x}{t+1} y(t) d t=0, \quad 0<x \leq 1
\end{aligned}
$$

with initial condition

$$
y(0)=0,
$$

and the exact solution is:

$$
y(x)=\ln (x+1) .
$$

Problem 2 (Kajani \& Vencheh 2007):

Consider the exponential type linear FIDE of first order

$$
\begin{aligned}
& y^{\prime}(x)-y(x)+\cos (2 \pi x)+2 \pi \sin (2 \pi x)+\frac{1}{2} \sin (4 \pi x)- \\
& \int_{0}^{1}(\sin 4 \pi x+2 \pi t) y(t) d t=0,0 \leq x \leq 1
\end{aligned}
$$

with initial condition:

$$
y(0)=1,
$$


where its exact solution is given as:

$$
y(x)=\cos (2 \pi x)
$$

To validate the efficiency of the method, three parameters are considered in numerical comparison such as number of iterations, execution time and maximum absolute error. As control comparison, standard or fullsweep conjugate gradient normal equations (FSCGNR) iterative methods is used as a control method. In addition, the results of standard Gauss-Seidel (GS) iterative method also presented to observe the performance and to demonstrate a broad analysis on the proposed method. All the simulations were implemented by a computer with processor Intel(R) Core(TM) 2 Duo CPU $2.4 \mathrm{GHz}$ and the algorithms codes were written in $\mathrm{C}$ programming. Throughout the simulations, the convergence test considered the tolerance error, $\varepsilon=10^{-10}$ and carried out on several different sizes on $n$. The numerical results of (1) and (2) have been recorded in Tables 1 and 2, respectively.

Table 3 shows percentage reduction for HSCGNR and proposed QSCGNR compared with FSCGNR. Based on the numerical results in Table 3, the number of iterations has decreased nearly 50 and $75 \%$ corresponding to HSCGNR and QSCGNR, respectively, compared with FSCGNR. Whereas, the execution time has reduced in the range of 75 and $90 \%$ for HSCGNR and QSCGNR, respectively, associated to FSCGNR iterative method. In term of accuracy, the QSCGNR slightly decreased as mesh size increases compared with FSCGNR and HSCGNR. This is because, the remaining points calculation are carried out based on average values. However, the accuracy of proposed method for both problems is in good agreement compared with the other existing methods.

\section{COMPUTATIONAL COMPLEXITY ANALYSIS}

The computational complexity of the FSCGNR, HSCGNR and QSCSNR iterative methods have been conducted to estimate the quantity of the computational work for each arithmetic operation performed per iteration for each iterative method. Based on Algorithm 1, the estimation in computing a value for each node point in the solution domain, the number of addition/subtractions (ADD/SUM) involved is $2(n / P)^{2}+6(n / p)-4$, while the multiplications/ divisions (MUL/DIV) is $2(n / P)^{2}+7(n / p)+2$. The total numbers of arithmetic operations per iteration for the FSCGNR, HSCGNR and QSCGNR iterative methods in solving (1) have been summarized in Table 4.

\section{CONCLUSION}

In this paper, we applied the QSCGNR method based on the corresponding CS-FD to solve first order linear FIDEs. Based on numerical simulations, it clearly demonstrates that there are promising improvements in number of iterations and execution time with implementing a QSCGNR iterative method compared to the FSCGNR and HSCGNR methods. Overall, the numerical results demonstrated that

TABLE 1. Comparison of number of iterations, execution time and maximum absolute error for the GS and family of CGNR iterative methods for (1)

\begin{tabular}{|c|c|c|c|c|c|}
\hline \multirow{3}{*}{ Methods } & \multicolumn{5}{|c|}{ Number of iterations } \\
\hline & \multicolumn{5}{|c|}{ Mesh size } \\
\hline & 60 & 120 & 240 & 480 & 960 \\
\hline GS & 1173 & 7869 & 16228 & 82314 & 222102 \\
\hline FSCGNR & 90 & 164 & 294 & 558 & 1096 \\
\hline HSCGNR & 46 & 85 & 146 & 276 & 544 \\
\hline \multirow[t]{2}{*}{ QSCGNR } & 23 & 44 & 74 & 140 & 269 \\
\hline & \multicolumn{5}{|c|}{ Execution time (s) } \\
\hline \multirow{2}{*}{ Methods } & \multicolumn{5}{|c|}{ Mesh size } \\
\hline & 60 & 120 & 240 & 480 & 960 \\
\hline GS & 312.13 & 1326.89 & 5350.32 & 14369.12 & 109887.15 \\
\hline FSCGNR & 0.26 & 0.78 & 3.58 & 24.17 & 201.86 \\
\hline HSCGNR & 0.12 & 0.29 & 1.31 & 6.75 & 64.2 \\
\hline QSCGNR & 0.04 & 0.14 & 0.76 & 2.32 & 8.19 \\
\hline \multirow[t]{2}{*}{ Methods } & \multicolumn{5}{|c|}{$\begin{array}{c}\text { Maximum absolute error } \\
\text { Mesh size }\end{array}$} \\
\hline & 60 & 120 & 240 & 480 & 960 \\
\hline GS & $2.208 \mathrm{E}-04$ & $8.211 \mathrm{E}-05$ & $4.362 \mathrm{E}-05$ & $8.366 \mathrm{E}-06$ & $6.012 \mathrm{E}-07$ \\
\hline FSCGNR & $9.120 \mathrm{E}-04$ & $1.557 \mathrm{E}-05$ & 5.297E-05 & $7.445 \mathrm{E}-06$ & $8.151 \mathrm{E}-07$ \\
\hline HSCGNR & 7.194E-04 & $9.120 \mathrm{E}-05$ & $1.557 \mathrm{E}-05$ & $5.297 \mathrm{E}-05$ & 7.445E-06 \\
\hline QSCGNR & $1.376 \mathrm{E}-03$ & 7.194E-04 & $8.681 \mathrm{E}-05$ & $1.557 \mathrm{E}-05$ & $5.297 \mathrm{E}-06$ \\
\hline
\end{tabular}


TABLE 2. Comparison of number of iterations, execution time and maximum absolute error for the GS and family of CGNR iterative methods for (2)

\begin{tabular}{|c|c|c|c|c|c|}
\hline \multirow[t]{2}{*}{ Methods } & \multicolumn{5}{|c|}{$\begin{array}{c}\text { Number of iterations } \\
\text { Mesh size }\end{array}$} \\
\hline & 60 & 120 & 240 & 480 & 960 \\
\hline GS & 1268 & 9637 & 18928 & 90228 & 246091 \\
\hline FSCGNR & 146 & 272 & 468 & 924 & 2259 \\
\hline HSCGNR & 74 & 134 & 238 & 468 & 1130 \\
\hline QSCGNR & 36 & 74 & 122 & 236 & 568 \\
\hline \multirow{2}{*}{ Methods } & \multicolumn{5}{|c|}{$\begin{array}{c}\text { Execution time (s) } \\
\text { Mesh size }\end{array}$} \\
\hline & 60 & 120 & 240 & 480 & 960 \\
\hline \multirow{4}{*}{$\begin{array}{c}\text { GS } \\
\text { FSCGNR } \\
\text { CGNR } \\
\text { QSCGNR }\end{array}$} & 425.69 & 5324.21 & 55324.20 & 155159.78 & 873214.21 \\
\hline & 0.56 & 1.71 & 7.82 & 44.25 & 286.20 \\
\hline & 0.27 & 0.52 & 2.41 & 11.27 & 71.26 \\
\hline & 0.10 & 0.21 & 1.24 & 3.98 & 18.38 \\
\hline \multirow[t]{2}{*}{ Methods } & \multicolumn{5}{|c|}{$\begin{array}{l}\text { Maximum absolute error } \\
\text { Mesh size }\end{array}$} \\
\hline & 60 & 120 & 240 & 480 & 960 \\
\hline GS & $3.584 \mathrm{E}-04$ & $6.235 \mathrm{E}-04$ & $2.378 \mathrm{E}-05$ & $4.331 \mathrm{E}-05$ & $1.203 \mathrm{E}-06$ \\
\hline FSCGNR & $3.593 \mathrm{E}-04$ & 8.901E-05 & $2.214 \mathrm{E}-05$ & $5.523 \mathrm{E}-06$ & $1.379 \mathrm{E}-06$ \\
\hline HSCGNR & $1.462 \mathrm{E}-03$ & $3.593 \mathrm{E}-04$ & $8.901 \mathrm{E}-05$ & $2.214 \mathrm{E}-05$ & $4.562 \mathrm{E}-06$ \\
\hline QSCGNR & 3.923E-03 & $1.462 \mathrm{E}-03$ & $3.593 \mathrm{E}-04$ & 8.901E-05 & $2.214 \mathrm{E}-05$ \\
\hline
\end{tabular}

TABLE 3. Percentage reduction of number of iterations and execution time of tested methods relative to FSCGNR methods in solving (1) and (2)

\begin{tabular}{cccc}
\hline Problems & Methods & Number of iterations $(\%)$ & Execution time $(\%)$ \\
\hline 1 & HSCGNE & $48.17-50.54$ & $78.77-95.94$ \\
& QSCGNE & $73.17-75.46$ & $53.84-72.07$ \\
2 & HSCGNE & $49.15-50.73$ & $51.78-75.10$ \\
& QSCGNE & $72.79-75.34$ & $82.14-93.57$ \\
\hline
\end{tabular}

TABLE 4. Number of arithmetic operations per iterations involved based on family of CGNR methods for both problems

\begin{tabular}{lcc}
\hline \multirow{2}{*}{ Methods } & \multicolumn{2}{c}{ Arithmetic operations per node } \\
& ADD/SUB & MUL/DIV \\
\hline FSCGNE & $2 n^{2}+6 n-4$ & $2 n^{2}+7 n+2$ \\
HSCGNE & $\frac{n^{2}}{2}+\frac{5}{2} n-4$ & $\frac{n^{2}}{2}+\frac{7}{2} n+2$ \\
QSCGNE & $\frac{n^{2}}{8}+\frac{5}{4} n-4$ & $\frac{n^{2}}{8}+\frac{7}{4} n+2$ \\
\hline
\end{tabular}

the quarter-sweep iteration concept in association with the CGNE iterative method is superior and it has reduced the computational complexity significantly.

\section{REFERENCES}

Abdullah, A.R. 1991. The four point explicit decoupled group (EDG) method: A fast Poisson solver. International Journal of Computer Mathematics 38: 61-70.
Abdullah, A.R. \& Ali, N.H.M. 1996. A comparative study of parallel strategies for the solution of elliptic pdes. Parallel Algorithms and Applications 10: 93-103.

Agarwal, R.P. 1983. Boundary value problems for higher order integro-differential equations, Nonlinear Analysis, Theory, Methods and Applications 7: 259-270.

Aruchunan, E. \& Sulaiman, J. 2013. Half-sweep quadraturedifference schemes with iterative method in solving linear Fredholm integro-differential equations. Progress in Applied Mathematics 5(1): 11-21. 
Aruchunan, E. \& Sulaiman, J. 2012a. Application of the centraldifference scheme with half-sweep Gauss-Seidel method for solving first order linear Fredholm integro-differential equations. International Journal of Engineering and Applied Sciences 6: 296-300.

Aruchunan, E. \& Sulaiman, J. 2012b. Comparison of closed repeated Newton-Cotes quadrature schemes with halfsweep iteration concept in solving linear Fredholm integrodifferential equations. International Journal of Science and Engineering Investigations 1(8): 296-300.

Aruchunan, E. \& Sulaiman, J. 2011a. Half-sweep conjugate gradient method for solving first order linear Fredholm integro-differential equations. Australian Journal of Basic and Applied Sciences 5: 38-43.

Aruchunan, E. \& Sulaiman, J. 2011b. Quarter sweep Gauss-Seidel method for solving first order linear Fredholm integrodifferential equations. Matematika 27: 199-208.

Aruchunan, E. \& Sulaiman, J. 2010. Numerical solution of second-order linear Fredholm integro-differential equation using generalized minimal residual (GMRES) method. American Journal of Applied Sciences 7(6): 780-783.

Aruchunan, E., Muthuvalu, M.S. \& Sulaiman, J. 2013. Application of quarter-sweep iteration for first order linear Fredholm integro-differential equations. AIP Conference Proceedings 1522: 168-175.

Aruchunan, E., Muthuvalu, M.S., Sulaiman, J., Koh, W.S. \& Akhir, M.K.M. 2014. An iterative solution for second order linear Fredholm integro-differential equations. Malaysian Journal of Mathematical Science 8(2): 158-170.

Avudainayagam, A. \& Vani, C. 2000. Wavelet-Galerkin method for integro-differential equations. Applied Numerical Mathematics 32: 247-254.

Barrett, R., Berry, M., Chan, T.F., Demmel, J., Donato, J., Dongarra, J., Eijkhout, V., Pozo, R., Romine, C. \& van der Vorst, H. 1993. Templates for the Solution of Linear Systems: Building Blocks for Iterative Methods. Philadelphia: Society for Industrial and Applied Mathematics.

Fedotov, A.I. 2009. Quadrature-difference methods for solving linear and nonlinear singular integro-differential equations. Nonlinear Analysis 71: e303-e308.

Hosseini, S.M. \& Shahmorad, S. 2003. Numerical solution of a class of integro-differential equations by the Tau method with error estimation. Applied Mathematics and Computation 136: 559-570.

Kajani, M.T. \& Vencheh, A. 2007. Solving linear integrodifferential equation with Legendre wavelets. International Journal of Computer Mathematics 81(6): 719-726.

Karamete, A. \& Sezer, M. 2002. A Taylor collocation method for the solution of linear integro-differential equations. International Journal of Computer Mathematics 79(9): 987-1000.

Kurt, N. \& Sezer, M. 2008. Polynomial solution of high-order linear Fredholm integro-differential equations with constant coefficients. Journal of the Franklin Institute 345: 839-850.

Maleknejad, K., Mirzaee, F. \& Abbasbandy, S. 2004. Solving linear integro-differential equations system by using rationalized Haar functions method. Applied Mathematics and Computation 155: 317-328.

Morchalo, J. 1975. On two point boundary value problem for integro-differential equation of second order. Fasciculi Mathematici 9: 51-56.

Muthuvalu, M.S. \& Sulaiman, J. 2011. Half-sweep arithmetic mean method with composite trapezoidal scheme for solving linear Fredholm integral equations. Applied Mathematics and Computation 217: 5442-5448.

Muthuvalu, M.S., Aruchunan, E. \& Sulaiman, J. 2013. Solving first kind linear Fredholm integral equations with semismooth kernal using 2-point half-sweep block aritmetic mean method. AIP Conference Proceedings 1557: 350-354.

Othman, M. \& Abdullah, A.R. 2000. An efficient four points modified explicit group Poisson solver. International Journal of Computer Mathematics 76: 203-217.

Rashed, M.T. 2003. Lagrange interpolation to compute the numerical solutions differential and integro-differential equations. Applied Mathematics and Computation 151: 869-878.

Ren, Y., Zhang, B. \& Qiao, H. 1999. A simple Taylorseries expansion method for a class of second kind integral equations. Journal of Computational and Applied Mathematics 110: 15-24.

Shahsavaran, A. 2012. On the convergence of Lagrange interpolation to solve special type of second kind Fredholm integro differential equations. Applied Mathematical Sciences 6: 343-348.

Sulaiman, J., Othman, M. \& Hasan, M.K. 2004a. A new halfsweep arithmetic mean (HSAM) algorithm for two-point boundary value problems. Proceedings of the International Conference on Statistics and Mathematics and Its Applications in Development of Science and Technology. pp. 169-173.

Sulaiman, J., Othman, M. \& Hasan, M.K. 2004b. Quarter-sweep iterative alternating decomposition explicit algorithm applied to diffusion equations. International Journal of Computer Mathematics 81: 1559-1565.

Sulaiman, J., Othman, M. \& Hasan, M.K. 2009. A new quartersweep arithmetic mean (QSAM) method to solve diffusion equations. Chamchuri Journal of Mathematics 1: 93-103.

Wang, W. \& Lin, C. 2005. A new algorithm for integral of trigonometric functions with mechanization. Applied Mathematics and Computation 164: 71-82.

Yalcinbas, S. \& Sezer, M. 2000. The approximate solution of highorder linear Volterra-Fredholm integro- differential equations in terms of Taylor polynomials. Applied Mathematics and Computation 112: 291-308.

Yalcinbas, S. 2002. Taylor polynomial solution of nonlinear Volterra-Fredholm integral equations. Applied Mathematics and Computation 127: 195-206.

Elayaraja Aruchunan*

Department of Mathematics and Statistics

Faculty of Science and Engineering

Curtin University, Perth WA6845

Australia

Mohana Sundaram Muthuvalu

Department of Fundamental and Applied Sciences

Universiti Teknologi PETRONAS

31750 Tronoh, Perak

Malaysia

Jumat Sulaiman

Faculty of Science and Natural Resources

Universiti Malaysia Sabah

88400 Kota Kinabalu, Sabah

Malaysia 
*Corresponding author; email: earuchunan@yahoo.com

Received: 14 August 2012

Accepted: 30 September 2014 